\title{
Meaning: lost, found or 'made' in translation? A hermeneutical approach to cross-language interview research
}

\author{
Barbara Fersch
}

\begin{abstract}
Qualitative research that includes interviews in languages foreign to the researcher(s) has become increasingly common. However, there is surprisingly little reflection on the methodological implications of such research practices. Furthermore, strategies on how to analyse cross- and multi-language interview material are lacking. The aim of this article is to present possible ways of handling these challenges, focusing mainly on analysis. I propose a hermeneutical approach to the issue. First, I will discuss the epistemological/methodological foundations of the approach before proposing some 'tools' to help practically tackle the 'problem' of analysis using the chosen methodological perspective. Rather than ignoring or trying to circumvent the question of foreign language and/or translation, in the proposed approach linguistic questions and questions of translation are the central focus.
\end{abstract}

Keywords: epistemology, methodology, hermeneutics, analysis, cross-language, translation

Please cite this article as:

Fersch, B. (2013). Meaning: lost, found or 'made' in translation? A hermeneutical approach to cross-language interview research. Qualitative Studies, 4(2): 86-99.

\section{Introduction}

No way to say warm in French. There was only hot and tepid. If there's no word for it, how do you think about it? And if there isn't the proper form, you don't have the how even if you have the words. Imagine, in Spanish, having to assign a gender to every object: dog, table, tree, can opener. Imagine, in Hungarian, not being able to assign a gender to anything. $\mathrm{He}$, she, it all the same word. Thou art my friend, but you are my king; thus the distinctions of Elizabeth the First's English. But with some oriental languages, which all but dispense with gender and number, you are my friend, you are my parent and YOU are my priest, and YOU are my king and You are my servant whom I'm going to fire tomorrow, if You don't watch it, and YOU are my king whose policies I totally disagree with [...] and who the hell are you anyway...?

Samuel R. Delany - Babel-17

Cross-language qualitative interview research has become increasingly common and in a growing number of research projects researchers are dealing with qualitative data collection and interpretation in more than one language. This probably does not come as a surprise at a time of ongoing globalisation. As the field's object of analysis is linguistic, the fact that two or 
more different languages are involved and that (most of the time) the researchers are not native speakers or do not even speak one or more of the languages involved but make use of translators, therefore appears as one aspect of the research design that must be handled by and reflected in the methodology. Thus, it is surprising how little the issue of foreign language is discussed and reflected on within the qualitative research community. As, for example, Temple and Edwards (2002, p. 2) put it:

There is little reflection on the implications for qualitative research of language difference and the use of third parties in communication across languages. This is a strange omission given that qualitative approaches are steeped in a tradition that acknowledges the importance of reflexivity and context.

Even in the field of social anthropology, a discipline with a long history of fieldwork in foreign countries and a particular interest in language and communication, methodological discussion of the topic has largely been omitted:

It seems rather ironic that ethnography, whose beginnings hearken back to the times of lone, mostly English speaking fieldworkers studying 'primitive' tribes in far-off places (the members of which most certainly did not speak English), appears to ignore the problematic issue of conducting research in a nonnative language. (Winchatz, 2006, pp. 84-5)

This lack of consideration can also be traced in concrete research practices, as Allison Squires (2009) found in her research review of nursing studies projects that faced some kind of language barrier and involved translation at some point in the research process: 33 out of the 40 examined studies contained multiple inconsistencies with regard to methodology, mainly stemming from a neglect of the issue of foreign language in the project design.

Despite a clear gap in qualitative research literature and the problematic negligence in research practice concerning language barriers and translation dilemmas, a small but growing academic debate has emerged in recent years. Several aspects have been addressed, such as questions of representation (Temple and Edwards, 2002; Temple and Young, 2004; Temple, 2005; Hole, 2007), translation techniques and their validity (Esposito, 2001), the development of interview guides in multilingual research projects (Larkin et al., 2007), and questions of methodology and epistemology (Hennink, 2008).

However, strategies for how to approach and analyse cross- and multi-language interview material remain lacking. This article aspires to contribute to filling this gap. The aim of this paper is to present a methodologically coherent way of handling the problem of analysis of cross-language qualitative (interview) data, including epistemological reflections as well as practical 'tools' for analysis. I propose a hermeneutical approach to the issue, rooted in Gadamer's (1989) insights into meaning, language and translation. Hence I will first discuss the epistemological/methodological foundations of the approach, before proposing methodological strategies for practically tackling the 'problem' of cross-language analysis on the basis of the chosen methodological perspective. Rather than ignoring or trying to circumvent the question of (foreign) language and multilingualism, in the proposed approach, linguistic questions and questions of translation are the central focus. Thus, I argue, foreign language interview material can be opened up to interpretation. Furthermore, both the issue of multilingualism and the role of the researcher (and contingently, the translator) become almost 'automatically' subjects of reflection, an angle strongly advocated by, for example, Temple and Young (2004). Finally, I will 
describe various methodological 'tools' and provide an example of the analysis process from one of my own research projects in order to illustrate the advantages of a hermeneutical approach.

\section{The hermeneutical perspective on meaning, language and translation}

As Holloway and Todres (2003) point out, epistemological viewpoints should guide our choice of methods and design in any research project. Furthermore, they argue, by 'applying and pointing out an epistemological position' (ibid, p. 355) in a coherent way the credibility and validity of the research findings are strengthened. Epistemological perspectives also play an important role in the treatment of cross-language interview material (see Hennink, 2008). In this article the proposed strategy and methods are rooted in hermeneutical epistemology. The specific perspective of hermeneutics is highly useful when it comes to foreign language data and translation dilemmas, particularly due to the discipline's view of bias and the dialogical dimension of understanding (see below). In order to clarify the background of the subsequently proposed approach, in this section I shall discuss four topics of hermeneutical epistemology, based on Gadamer's considerations in Truth and Method (1989). In a nutshell these are (1) the hermeneutical conception of the relationship between understanding and interpretation; (2) the hermeneutical stance on fore-meanings, biases or prejudices; (3) the dialogical dimension of understanding; and (4) translation as a 'greater hermeneutical difficulty'.

Hermeneutics sees reality as humanly interpreted, as referring to meanings acquired through life experience (1). However, the mere insight that any reality, any knowledge and any 'truth' that can be found is human interpretation does not make a given approach hermeneutical. What characterises a hermeneutical approach is that it not only acknowledges that any reality is human interpretation, but also interprets this interpretation as (an) interpretation (itself) (Jung, 2001). Thomas A. Schwandt (2000) stresses this insight and elaborates on its everyday implications. According to Schwandt, in hermeneutic philosophy, understanding is seen as the

very condition of being human. Understanding is interpretation. As Gadamer (1970) explains, understanding is not 'an isolated activity of human beings but a basic structure of our experience of life. We are always taking something as something. That is the primordial givenness of our world orientation, and we cannot reduce it to anything simpler or more immediate.'(Schwandt, 2000, p. 194, emphasis in original)

This also means that, from a hermeneutical perspective, the standpoint of the 'uninvolved observer' is not an option for the researcher. In the context of a multilingual research field, this means that the relative familiarity of the researcher with the languages involved in the research project also has an impact on the interpretation process.

In this view, the researcher brings his/her own experiences and fore-meanings (Vorverständnis) to the interpretation process (a Vorverständnis that is influenced not a little by language) (2). However, in hermeneutics this is not a problem per se: Hermeneutics does not evaluate prejudices, bias or fore-meanings as necessarily negative for the research process. In contrast to phenomenological efforts to get rid of bias and prejudice by being an uninvolved observer, hermeneutical theory argues that one's biases should be utilised in the quest for understanding. In hermeneutics, trying to get rid of these fore-meanings is an impossible undertaking as they are something internal and quintessential to every individual, including researchers. As Gadamer puts it: 
In fact history does not belong to us; we belong to it. Long before we understand ourselves through the process of self-examination, we understand ourselves in a self-evident way in the family, society and state in which we live. [...] This is why the prejudices of the individual, far more than his judgements, constitute the historical reality of his being. (Gadamer 1989, p. 278, emphasis in original)

This quotation demonstrates the insuperableness of one's biases from a hermeneutic viewpoint, which is of special relevance in cross-language research projects. Since language and language use are part of culture and embedded in society, the bias stemming from 'tradition', that is, the specific background of the researcher in a multilingual research field, is inevitable.

In his article on inter-cultural research, Jan Kruse (2009) provides us with an example of how the differing backgrounds of the interviewee and interviewer can 'clash' even in a monolingual interview context. His example refers to an interview conducted in German of a Lebanese migrant woman living in Germany by a native German university student. Kruse shows how the different understandings and traditions concerning the process of finding a spouse or life partner can be traced in language use and certain respectively different understandings of the words 'partner', 'husband', 'meet someone' and 'dating'. Thus he offers the hermeneutical insight that it is not only the interviewees who necessarily understand themselves in the context of 'the family, society and state they live in', but also the interviewer and/or researcher who is biased by their personal upbringing and biography. We can easily imagine that this effect could play an even bigger role in research contexts where two or more languages are involved.

As noted above, this is not problematic for hermeneutics as such. The hermeneutic treatment of this problem lies in the engagement of these biases:

The point is not to free ourselves of all prejudice, but to examine our historically inherited and unreflectably held prejudices and alter those that disable our efforts to understand others, and ourselves. (Garrison in Schwandt, 2000, p. 195)

Gadamer states that this bias should be examined and analysed in the engagement process:

[...] it is quite right for the interpreter not to approach the text, relying solely on the foremeaning already available to him, but rather explicitly to examine the legitimacy - i.e., the origin and validity - of fore-meanings dwelling within him. (Gadamer, 1989, p. 270)

However, the fact that we cannot free ourselves and our quest for understanding from such biases and prejudices does not mean that we necessarily seek only to reproduce them: on the contrary, the hermeneutical approach seeks to gain understanding by critically reflecting on such biases and prejudices. The hermeneutical research process entails that 'the interpreter risks those prejudices in the encounter with what is to be interpreted' (Schwandt, 2000, p. 195).

To sum up, reflecting upon and examining one's own fore-meanings is a necessary precondition for any researcher applying a hermeneutical approach, including those that are connected with language and language use. In a multilingual research context, questions of language and meaning are often connected to questions of translation as well - thus fore-meanings stemming from translation should become a subject for reflection, too.

Schwandt (ibid) stresses the dialogical dimension of understanding: prejudices and biases are 
risked in confrontation with the alien or unknown meaning, and this happens in a dialogical and interactive manner - this is the third relevant point in this section (3). This focus on interaction, which ascribes action to the interpreter as well, challenges the classical view that interpretation aims to reproduce meaning as immanent to the given object of interpretation. In hermeneutics, on the other hand, interpretation is seen as the production of meaning; which means that this meaning is produced through the involvement of the interpreter in the aforementioned dialogue. Thus, meaning is produced in a mutual negotiation between the interpreter and the object to be interpreted (see, for example, ibid; Jung, 2001).

This emphasis on the role of the interpreter in the production of meaning implies several consequences for cross-language research: If interpretation is part of the production of meaning, then cross-language interpretation dilemmas are also part of the process of 'making' meaning. And if the process of interpretation is part of the production of meaning, what about the process of translation? Is translation also a form of interpretation, and thus also of the production of meaning?

In Truth and Method, Gadamer takes up the issue of foreign languages (4) and writes about the question of translation, which, for him, is mainly an especially challenging instance of the whole problem of understanding:

The fact that a foreign language is being translated means that this is simply an extreme case of hermeneutical difficulty - i.e., of alienness and its conquest. In fact all the 'objects' with which traditional hermeneutics is concerned are alien in the same unequivocally defined sense. The translator's task of re-creation differs only in degree, not in kind, from the general hermeneutical task that any text presents. (Gadamer, 1989, p. 389)

Gadamer identifies understanding, as such, as the focal point of the hermeneutic problem in the search for knowledge. Thus, understanding and interpretation in a language foreign to the researcher meet with the same kind of difficulties as in the mother tongue. Although focused on finding understanding, the hermeneutical perspective does not assume that meaning can only be discovered in one's own mother tongue. Likewise, a translator is also engaged in the process of understanding and interpretation. Hence, translators working on a multilingual research project participate in the production of meaning, too.

Taking especially the two last points into account, a hermeneutical approach to multi-language research means that the production of meaning in translation should be taken into account in one way or another in the research design and the analysis. Thus, the fact that translators have in some way been involved or that interpretation has taken place in a language that is foreign to the researcher cannot be ignored or left out - in order to reach understanding, this fact should be included in the analysis and thoroughly reflected on. In addition, hermeneutical crosslanguage researchers should try to find a way to examine their biases and fore-meanings, especially in the face of foreign language interview material.

In what follows I will present a proposal on how to grasp and tackle multilingual qualitative data under the premise of the hermeneutical perspective. I will argue that an appropriate way to inspect biases and fore-meanings on the one hand, and to adequately shed light on the production of meaning in interpretation and translation on the other, is to include a focus on questions of language, language use and linguistic phenomena. 


\section{Approaching the 'greater hermeneutical difficulty'}

As outlined above, hermeneutics urges us to inspect and reflect on our biases and foremeanings, as well as the production of meaning in processes of interpretation and translation. In the case of multilingual interview research, this can become more complex and challenging because of the 'greater hermeneutical difficulty'. How can we approach the analysis of multilingual qualitative data? How can we make the production of meaning in translation transparent and reflect on it? What methodological tools can be applied to grasp the 'greater hermeneutical difficulty'?

For a methodological-practical conceptualisation of interview analysis, Jan Kruse (2009) proposes taking the 'principle of openness' (ibid, para 18, author's translation) seriously. By 'principle of openness', Kruse means remaining reticent concerning our own systems of relevance, biases and fore-meanings (but not completely restraining them, as this is neither possible nor desired from a hermeneutical perspective - see the discussion above) when approaching empirical material. He argues that this is only possible if we sensitise ourselves to our own system of relevance. For Kruse, this has two implications for research practice: firstly, fore-meanings and knowledge stemming from the study of research literature should influence our empirical research in a heuristic and not a deterministic manner; secondly, we should reflect upon our concepts of relevance and their influence on the research process. In other words, we must be thoroughly reflective concerning our ways of understanding and interpreting in order to understand the 'alien'. Kruse writes:

Because otherwise we do not understand anything of the alien system of meaning, or rather only what fits with us, and therefore only what we already knew beforehand. (Ibid, paragraph 18, author's translation)

And what does not fit, because we do not know about it, will - as the pragmatics of everyday life shows us - be made to fit. (Ibid, footnote to paragraph 18, author's translation)

Sensitising oneself to one's own system of relevance and its influence on the research process, however, can become more complex in the face of multilingual interview research. For instance, semantic and linguistic fore-meanings and biases that stem from the researcher's native tongue can have an impact on the analysis of the foreign language interview material. Words translated into another language may have profoundly different connotations. How can we systematically include reflection on this in the process of analysis? On the other hand, the fact that the researchers might not be as familiar with connotations as native speakers might lead to a more thorough inspection of them and prevent them from all-too-early interpretations, which might be more tempting in one's mother tongue. In this sense, foreign language interview interpretation may not solely create problems, but offer opportunities or even advantages.

Where external translators are involved, this also requires sensitivity to the translators' biases and fore-meanings. Temple and Edwards (2002) offer an illustrative example of how translators' biases can play a role in the research process: In a research project on homeless families and their use of children's health services in Great Britain, the researcher employed several translators, as a substantial number of the interviewed homeless families were migrants with little or no English language proficiency. Amongst others, a Bengali/Sylheti translator was hired to translate during the interviews of migrant families from Bangladesh. The translator, a migrant from Bangladesh herself, strongly emphasised her own middle-class background in 
contrast to those of the interviewees:

As she interpreted the interviewees' accounts of their difficulties and traumas in accessing and using child health services and other facilities, and chose the words best suited to convey their meaning to me, she constructed their social location [...] in opposition to her own in significant ways. (Ibid, p. 14)

This example clearly shows how much of an influence the translator's fore-meanings can have and how s/he participates in the production of meaning.

Hence, sensitivity to one's own and the (hired) translator's systems of relevance, especially with regard to language and translation issues, appears to be necessary. How, then, can we thoroughly reflect on these issues throughout the research process and in the analysis? Is it possible to systematically include tools in order to ensure that this sensitivity is included? In the following section I will propose and discuss some tools which I consider useful in the analysis of multilingual qualitative interview material.

In their article, Temple and Young (2004) distinguish between two general possibilities in multilingual interview research, namely research in which researchers also translate on the one hand (dual researcher/translator role) and research in which researchers hire external translators for interviewing and translation (researcher plus translator). However, as I will argue, this dichotomy overlooks several other possibilities for interview research in a multilingual field. For instance, if the researchers themselves are fluent in all languages involved, the challenge might not be translation, but interpretation in a language that is not the researcher's native tongue. ${ }^{1}$ In what follows, I will propose several ideas and instruments that have been applied in the latter case. Such tools can, however, also be useful when external translators are employed.

\section{Investigating meaning 'made' in translation}

In this section I will elaborate on the ways in which it is possible to handle qualitative (interview) material that is to be analysed in a language foreign to the researcher. I will present an analysis design of my own which I applied when carrying out analysis in a language foreign to me (Fersch, 2009). As mentioned above, I will argue that instead of ignoring or circumventing questions of language and translation, a special emphasis on these issues is beneficial.

Here, the challenge - as noted above - is mainly that the interview material on hand is in a language foreign to the researcher. The researcher, then, should be careful to not impose meanings and connotations from his/her native tongue on the analysis. Furthermore, s/he should sensitise him/herself to the biases and fore-meanings stemming from the cross-language analysis setting. One possible way of systematically reflecting on these topics during analysis is to include some kind of 'semiotic analysis' (Coffey and Atkinson, 1996, p. 83).

A semiotic analysis can include the investigation of several linguistic elements, such as figurative language (e.g. metaphors) and the use of words. In their account, Coffey and Atkinson suggest

that a sensitive examination of such aspects of language use can illuminate how individuals

\footnotetext{
${ }^{1}$ However, translation issues will certainly arise at other stages of the research process.
} 
and groups organize and express their experiences. (Coffey \& Atkinson, 1996, p. 84)

As regards the issue of figurative language and metaphors, George Lakoff and Mark Johnson (2003) have argued that not only our language but also our thinking, our concepts and our behaviour can be comprehended by way of the notion of 'metaphor':

\begin{abstract}
Metaphor is for most people a device of the poetic imagination and the rhetorical flourisha matter of extraordinary rather than ordinary language. Moreover, metaphor is typically viewed as characteristic of language alone, a matter of words rather than thought or action. For this reason, most people think they can get along perfectly well without metaphor. We have found, on the contrary, that metaphor is pervasive in everyday life, not just in language but in thought and action. Our ordinary conceptual system, in terms of which we both think and act, is fundamentally metaphorical in nature. (Ibid, p. 3)
\end{abstract}

Thus, a thorough examination of the figurative language used in certain interviews or narratives can give an insight into how meaning is created in the use of language.

The same is true for the examination of the use of words. The meaning of certain words and terms in the specific context of a certain narrative becomes understandable not only in the situative context of the respective interview but also necessarily in the broader context of the culture, language and society within which it is placed (see, for example, Mannheim, 1982; Kruse, 2009).

The systematic application of such tools to foreign language interview material enables a constant reflection to take place on the language and linguistic devices that might be unfamiliar or difficult to understand for the non-native researcher. Furthermore, it provides a useful contribution to further analysis and discussion.

In the case of foreign language interview analysis, the inclusion of some additional methodological tools appears beneficial, such as consulting the relevant dictionaries and idiom lexicons and a discussion of meaning with native speakers. A semiotic analysis, then, helps to identify passages, figurative language and/or words and terms that are ambiguous to the researcher, which can then be discussed with native speakers and researched in dictionaries. Discussion will certainly open up more dimensions of meaning than dictionaries, as situative aspects and immediate context can be taken into account.

This modus operandi proved to be highly productive during my $\mathrm{PhD}$ research into new media freelancers in Denmark and Germany, a project that included qualitative interviews in both German (my, the researcher's, mother tongue) and in Danish (a foreign language for me as the researcher) (Fersch, 2009). As a non-native Danish speaker (albeit literate to a fairly high level) I collected and analysed several work-biographical interviews from freelancers in Denmark. There were several instances in which the described strategy contributed to interpretation concerning the use of words and their connotations or idiomatic language. Embedded in the overall hermeneutic approach, which additionally included a focus on the context of each interview, was a reflection on the interview's context and the researcher's role and contribution. In the following I provide a detailed presentation of the analysis process concerning one specific (and very important) topic. This process of analysis includes both mother-tongue interview material (in German) and non-mother-tongue interview material (in Danish). It provides a description of the overall approach to the analysis, starting with reflections on the interview 
design and collection process. As we will see, the inclusion of a closer look at linguistic phenomena in both languages proved to be crucial to the final interpretation. ${ }^{2}$ For the sake of clarity, I will provide some contextual information about freelancing and the interviewees.

One of the most central and interesting findings of the research project (Fersch, 2012) was established due to the overall hermeneutical approach, which, among other aspects, included the analysis of language use: the profound difference ${ }^{3}$ between the Danish and German freelancers interviewed concerning the role and relevance of insecurity ${ }^{4}$ in their narratives. From very early on in the research process, during the interview phase, I was confronted by a very strange difference in talking about the topic of insecurity - whereas it was a very significant issue for the German freelancers, the Danish freelancers did not seem as bothered by it. At this point I was confronted with my own German background: As I have - at least partly been inspired by German research literature and had developed the research idea with the situation of German freelancers in mind, I had initially had some expectation that the issue of insecurity was going to play a role in the interviews. As I began with the interviews in Germany, these expectations were confirmed.

Therefore when it came to Denmark, I was already experienced in 'freelancer interviewing' and I had established routines and expectations of how such interviews would develop. In other words (in hermeneutical terminology), when approaching the interviews I had already established fore-meanings, which were then challenged by the ongoing research process.

The main difference in the organisation of speech and narration was that the German freelancers (in contrast to the Danish freelancers) brought up and problematised the topic of insecurity both unsolicited most of the time and very early on in the interviews. This was especially clear in the interview with Petra 5 , a 40-year-old freelancer located in the Ruhr area of Germany, whose narration was strongly characterised by de-problematising nearly all of the potentially problematic topics in the interview. Nevertheless, insecurity was the only topic she herself presented as a problem, defining it as the one big disadvantage of freelancing as a work form. She brought up the topic when asked about the advantages and disadvantages of freelancing, stating:

The disadvantage is, of course, that one never knows when the next job is coming in.

${ }^{2}$ Here, again, I have been confronted with translation dilemmas, as I have had to translate idioms and specific terms, plus my understanding and interpretation of them in two different languages, into yet another - English. In the interview quotes normally used for publications in English idiomatic language has been translated freely, according to meaning. However in the two instances used to illustrate the analysis process, terms and idioms have been translated directly into English and the original German and Danish quotes are provided as well, in order to provide insights into the process of analysis.

${ }^{3}$ The interviews were collected in summer 2007 (Germany) and spring 2008 (Denmark), before the financial crisis became perceptible in both countries.

${ }^{4}$ Freelancers, or the solo-self-employed, who pursue a profession without any long-term commitment to a particular employer, constitute one of the most flexible parts of the workforce. As they have to sell their services on the market without being buffered by an employer, they are very directly exposed to market risks. Hence the assumption that insecurity might constitute a problem for them.

${ }^{5}$ All names used are pseudonyms. 


\section{[...] there is always this uncertainty [...]}

After having introduced and problematised the topic of insecurity, the German freelancers subsequently describe a lot of strategies and actions they undertake in order to deal or cope with this problem. And they actually do 'do' a lot in order to cope with it. For example, Madhi, another freelancer in the Ruhr area, talked about two dimensions of the 'insecurity problem' and identified two ways of handling it. The first one is a strategy applied to his working life, of acquiring additional customers or jobs as a 'back-up' to protect against meagre times. This has not proved to be a purely positive strategy, as Madhi described the effect of it in busy times as leading to a lot of stress and to the need to pass some jobs or orders onto others:

\section{[...] and then, however, we were somehow partly afraid, and that was the mistake I think, to somehow continue to acquire jobs right in the middle and despite the high order volume, right?}

The other dimension Madhi addressed refers to the more emotional or 'coping' side of the problem. In one part of the interview, he spoke at some length about his coping strategies. These can be summed up as 'bearing up', 'feigning ignorance' and 'fatalism'. Madhi states at one point:

You know, it is all about emotional states, right? [...] If you do something like that [=freelancing, author] I think you have to bring with you a portion of stupor, as I would call it and maybe as well a bit of (.) trust in God or something, you know, accepting your fate or something like that, by saying 'oh, every cloud will somehow have a silver lining' and so on; [...] If you take everything too seriously [...] I don't think you are going to be happy with it.

As this example illustrates quite well, the question of insecurity is thus a big issue, which obviously requires a lot of 'work' or activity from the German freelancers in order for it to be dealt with. This problem and all of its consequences can be found in different forms or embodiments in all of the German cases.

The use of specific words by Nina and Elena (both freelancers from Berlin) in this context is also rather interesting: Nina talked about 'Existenzangst' and how she had learned to cope with it, and Elena described how the problem of insecurity had recently become 'existenziell' (existential) for her family. Here a closer look at the connotations and language use appears promising: Although one connotation of Existenzangst refers to a more philosophical understanding of the fear of not living a life that makes sense or has meaning, a second, much more everyday understanding of the word, refers to the fear of losing one's livelihood or being ruined economically. Parallel connotations also exist for the word existenziell, including one 'concerning one's livelihood' (Duden online, n.d. a and b). The context of the two interviews makes it very plausible to conclude that the latter is the connotation to which the interviewees are referring.

While interviewing the Danish freelancers, however, the topic of insecurity was almost never mentioned unsolicited (with the exception of Susanne, which is why I will discuss her case more closely later on in this section). With growing irritation over the fact that the interviews were not 'functioning' the way I was used to, I started to ask directly about the topic. When explicitly asked about it, some of the Danish freelancers talked about the insecurity inbuilt in 
the freelancing work form and the strategies they applied to combat it. However the topic was never assigned the relevance, gravity and existentiality that it was by the German interviewees. Furthermore, and despite being directly asked about it, the Danish freelancers did not talk very much about the topic. For instance, Morten, a freelancer based in Århus, described how he always has a financial cushion equal to a few months' income in his bank account. However, he emphasised that this is not in any way a conscious or active strategy:

I have actually not so much thought about that, so, this is actually a bit unconscious, I think. [...] It is running how it is running on a somehow unconscious level. So it's not like I actively think a lot about how much [money] it should be because of this and that.

When it comes to the question of whether this financial insecurity and uncertainty makes him feel afraid, he strongly denied it. Another Danish freelancer, Christian from Copenhagen, uses his savings in a similar kind of security strategy in the context of the 'bulimic career patterns' of freelance work. This gives him the chance to be a little bit more relaxed,

because I know very well that I am not screwed. This makes it possibly less hectic for me if I lose a bit of money in one month.

The only Danish freelancer who brought up the topic of insecurity and uncertainty herself is the aforementioned Susanne, who is a 43-year-old freelance graphic designer who lives in Copenhagen. However, on closer inspection of her situation there are several biographical reasons why she might be more sensitive to issues of insecurity (shorter experience with fulltime freelancing, being single mother, etc.). She mentioned the topic of insecurity when asked about the advantages and disadvantages of being employed in contrast to freelancing:

So, the advantage of being employed clearly is that you get the feeling of having a secure framework. Whether this is fake or not does not matter. It is a secure framework you are in. Your pension is taken care of. So on and so forth. But I had been working as an employee at the theatre for 12 years when we closed down the department I started in. So in this way I would say I don't trust the [...] 'employee labour market' very much. For me, in the graphical branch, it is just as unstable as freelancing.

Thus Susanne suggests that a (feeling of) security is indeed of relevance for her, and that it is in some way missing for her as a freelancer. Aside from this, based on her experience, she does not view 'employee security' as 'real security' any more, as she defines instability and insecurity as something inherent in her branch of industry and not in the work form. In other parts of the interview it becomes clear that it is again the 'bulimic career patterns' which are a source of insecurity for her. In contrast to Morten, for example, she has installed some quite thoroughly thought-through security mechanisms, which she also describes in depth in the interview. By reporting these reflected and thought-through safeguards against times with low orders or job offers, her interview differs from the other Danish interviews.

Hence, we can sum up that insecurity indeed constitutes a problem for Susanne, and that she has also created some mechanisms to safeguard against it. The subsequent course of action in the analysis process was to establish if there was any feeling of fear or anxiety connected with the reported problem of insecurity. When asked directly if this insecurity was also connected with fear or the feeling of being afraid, her answer was (directly translated from Danish): 
At this point of the analysis a closer look at the meaning of this expression was very useful. Following the lexicon (Den Danske Ordbog n.d.), to 'go from house and home' means that someone is, because of economic problems, forced to leave or sell one's own house. Thus, it means to leave one's house in the literal sense. However, in additional discussions with native speakers it was also mentioned that it can be used more generally in the sense of meaning 'sinking into poverty'. This interpretation made sense in the direct context of the remark, in which Susanne says:

I am afraid, because it is so difficult to come back [...] in such a creative branch. If you have been dropping out, if you get on the wrong track, then there is not so much that sticks to you. And then that's just how it is.

This contrasting comment indicates that what Susanne is afraid of is not risking her livelihood, but of becoming excluded from the creative field or industry. In her presentation the issue of insecurity appears to be less dangerous, and the connected fears less serious, than in the case of the German freelancers. Therefore, even though insecurity plays a role in her account on working and living with freelancing, the difference presented previously (though maybe in an alleviated form) between the Danish and German freelancers' accounts on the topic of (in)security remains in her case.

\section{Conclusions}

With this article I have aimed to contribute to a discussion of the methodological implications of cross-language interview research and to present a proposal for how to approach the analysis of such interview research material. Grounding the proposal in hermeneutical epistemology, the production of meaning in translation and the need for its reflection has been emphasised. In order to thoroughly inspect the fore-meanings connected to language and to make the contribution of researcher(s) (and translator(s)) in the production of meaning transparent I have argued that, amongst other things, the inclusion of elements of linguistic analysis is highly useful. In this article I have given an example from my own analysis on how the inclusion of a close look at the use of words and idiomatic language within the analysis process proved to be extremely helpful.

1) The reflection of the researcher's production of meaning, which, according to Gadamer and the hermeneutical perspective, is a crucial part of the hermeneutic methodology, took place in several stages of the interview process: The expectation of the importance of insecurity, stemming from my, the researcher's, own background and the research literature used, was somewhat not reflected upon at the start of the interview collection process. This was challenged by the interview experience in Denmark. As a consequence of this, I began to ask directly about the topic in the interviews, thereby actively 'imposing' the topic on the interviewees. Here my (the researcher's) share in the production of meaning became very clear. In the following process of analysis, this selfreflection was used to further develop the argumentation that a profound difference in the importance of insecurity in the interviewees' narratives could be found along country lines. This could be found not only in the content but also in the structure and dynamics of the interviews: Whereas in Denmark the topic had to be 'imposed' on the

\footnotetext{
${ }^{6}$ In Danish: Jeg er ikke bange for, at jeg skal gå fra hus og hjem.
} 
interviewees, this was not at all the case in Germany, where it was a major issue that was almost always brought up by the interviewees themselves.

2) As the next analytical step I looked more closely at the only Danish 'outlier' concerning the topic of insecurity, in order to clarify if the abovementioned difference might or might not be found here too. In this process of comparison, linguistic analysis was used, both for the native (German) language material as well as for the non-native (Danish) material. Here it became clear that there was a difference concerning the fears and anxieties connected to the topic of insecurity - even the Danish outlier was not afraid of losing her livelihood, whereas this was a major issue for the German freelancers. The interviewees' use of words and idioms ('existential fear' vs. 'not being afraid to go from house and home') and its thorough clarification made these differences between the interviewees very clear and provides further evidence for this interpretation.

A hermeneutical approach thus provides a helpful method for cross-language (and cross-culture) qualitative research. The focus of hermeneutics on the production of meaning, which includes the researcher, is especially useful here. Elements of linguistic analysis, however complicated they may seem, are a highly useful instrument for the hermeneutical analysis of cross-language interview material.

\section{References}

Coffey, A. \& Atkinson, P. (1996). Making Sense of Qualitative Data. Complementary Research Strategies. London: Sage.

Delany, S. R. (1966). Babel-17. New York: Ace Books.

Duden online. (n.d. a). Existenzangst. Accessed at

http://www.duden.de/rechtschreibung/Existenzangst on 19 July 2013.

Duden online. (n.d. b). Existenziell. Accessed at

http://www.duden.de/rechtschreibung/Existenzangst on 19 July 2013.

Esposito, N. (2001). From meaning to meaning: The influence of translation techniques on nonEnglish focus group research. Qualitative Health Research, 11 (4): 568-79.

Fersch, B. (2009). Work and Life Patterns of Freelancers in the (New) Media: A Comparative Analysis in the Context of Welfare State and Labour Market Regulations in Denmark and Germany. Aalborg: Institut for Sociologi, Socialt Arbejde og Organisation, Aalborg Universitet.

Fersch, B. (2012). 'German Angst' vs 'Danish Easy Going'? On the Role and Relevance of Insecurity and Uncertainty in the Lives of Freelancers in Denmark and Germany Sociology, 46(6), 1125-1139.

Gadamer, H. (1989). Truth and Method. London: Continuum.

Glaser, B. G. \& Strauss, A. L. (1999). The Discovery of Grounded Theory. Strategies for Qualitative Research. London: Aldine Transactions.

Hennink, M. (2008). Language and communication in cross-cultural research. In P. Liamputtong (Ed.), Doing Cross-Cultural Research: Methodological and Ethical Perspectives. Dordrecht: 


\section{Springer.}

Hole, R. (2007). Working between languages and cultures: Issues of representation, voice and authority intensified. Qualitative Inquiry, 13 (5): 696-710.

Holloway, I. \& Todres, L. (2003). The status of method: Flexibility, consistency and coherence. Qualitative Research, 3 (3): 345-57

Den Danske Ordbog. (n.d.). Hus. Accessed at http://ordnet.dk/ddo/ordbog?query=hus on 19 July 2013.

Jung, M. (2001). Hermeneutik zur Einführung. Hamburg: Junius Verlag.

Kruse, J. (2009). Qualitative Sozialforschung - interkulturell gelesen: Die Reflexion der Selbstauslegung im Akt des Fremdverstehens. Forum Qualitative Sozialforschung [Forum: Qualitative Social Research], 10 (1): Art. 16. Accessed at http://nbnresolving.de/urn:nbn:de:0114-fqs0901162 on 14 February 2009.

Lakoff, G. \& Johnson, M. (2003). Metaphors We Live By. Chicago: University of Chicago Press.

Larkin, P. J., Dierckx de Casterlé, B. \& Schotsmans, P. (2007). Multilingual translation issues in qualitative research: Reflections on a metaphorical process. Qualitative Health Research, 17 (4): $468-76$.

Mannheim, K. (1989). Structures of Thinking. London: Routledge.

Squires, A. (2009). Methodological challenges in cross-language qualitative research: A research review. International Journal of Nursing Studies, 46: 277-87.

Schwandt, Thomas A. (2000). Three epistemological stances for qualitative inquiry: Interpretivism, hermeneutics and social constructivism. In: N. K. Denzin \& Y. S. Lincoln (Eds.), Handbook of Qualitative Research ( $2^{\text {nd }}$ edn.). Thousand Oaks: Sage Publications.

Temple, B. \& Edwards, R. (2002). Interpreters/translators and cross-language research: Reflexivity and border crossings. International Journal of Qualitative Methods, 1 (2): Art. 1. Accessed at http://www.ualberta.ca/ ijqm/ on 1 February 2010.

Temple, B. \& Young, A. (2004). Qualitative research and translation dilemmas. Qualitative Research, 4 (2): 161-78.

Temple, B. (2005). Nice and tidy: Translation and representation. Sociological Research Online, 10 (2). Accessed at http://www.socresconline.org.uk/10/2/temple.htm on 1 February 2010.

Winchatz, M. R. (2006). Fieldworker or foreigner? Ethnographic interviewing in nonnative languages. Field Methods, 18 (1): 83-97.

Author

Barbara Fersch is an assistant professor at the Centre for Comparative Welfare Studies, Department of Political Science at Aalborg University, Denmark. Email: Fersch@dps.aau.dk 